\title{
Strain-hardening Ultra-high Performance Fibre Reinforced Concrete: Deformability versus Strength Optimization
}

\author{
E. Denarié and E. Brühwiler \\ Maintenance, Construction et Sécurité des ouvrages, (MCS-IIC-ENAC), Ecole Polytechnique Fédérale de \\ Lausanne (EPFL), Switzerland \\ Corresponding author: E. Denarié, e-mail: emmanuel.denarie@epfl.ch
}

\begin{abstract}
High Performance Cement-based composites such as some UHPFRC or SHCC exhibit a tensile strain hardening response associated to the progressive formation of finely distributed microcracks. Strain Hardening (SH) - UHPFRC with suitable fibrous mixes have a dense matrix, a very low capillary absorption of liquids, significant viscoelastic potential and limited shrinkage. They exhibit a tensile strain hardening response up to $0.3 \%$. Strain hardening materials are candidates for improving existing or new structures to increase their durability and mechanical performance. With this aim in view, the impact of macro and microcracking on the protective function and corrosion mechanisms in cementitious materials has to be critically weighed to choose adequate materials in terms of strength and deformability, to fulfil durability requirements. From this basis, the mechanical response (strength, deformability and associated crack formation) can be tailored according to the applications. Finally, future steps for the development and applications of these advanced contemporary materials can be defined.
\end{abstract}

Keywords: strain hardening, UHPFRC, deformability, protective function, crack formation 


\section{Introduction}

The emergence of new materials or combinations of materials, with improved properties, has always been a source of progress in civil engineering. Classical examples are the development of binders and fibre reinforced composites from very ancient times, and more recently the inventions of reinforced concretes, prestressed concretes and fibre reinforced concretes in the 19 and $20^{\text {th }}$ centuries.

During the last 30 years, three major developments took place:

- The first one is, starting with the pioneering works of Bache [1], the increase of the compressive strength and to a lower extend of the tensile strength to achieve cementitious composites capable of $200 \mathrm{MPa}$ in compression and up to more than $20 \mathrm{MPa}$ in direct tension with on one hand DSP, $\mathrm{CRC}^{\circledR}[1]$, and later UHPFRC [2-6], and on another hand Slurry Infiltrated Cementitious composites [7-9].

- The second one is the increase of the deformability to achieve cementitious composites with a tensile strain hardening from several $\%$ (for some Strain hardening UHPFRC) $[3,5]$ to several \% (for SHCC and Slurry infiltrated Fibre or Mat Reinforced Composites) [10-12], and [7-9].

- The third one is the improvement of the workability to achieve self-compacting concretes [13].

From a more fundamental point of view, the associated progresses were linked to: (1) a deeper understanding of the rheological behaviour of cementitious materials, the optimization of their granular packing and their interactions [14-15], (2) the development of criteria for strain hardening $[10,16],(3)$ the optimized design of fibre reinforcements [3], with multilevel fibre combinations.

All developments on the improvement of deformability of cementitious composites with tensile strain hardening $(\mathrm{SH})$ are uniquely associated with the progressive creation of very finely distributed microcracks (SHCC and SH-UHPFRC). It is thus of primary importance to determine how those materials can be used at Serviceability (SLS) also in their strain hardening - finely microcracked domain.
Cracks and their influence on durability have been a matter of interest for many years. Many construction codes still impose crack width limitations for reinforced concrete structures according to the severity of the exposure. However, it is now clear that the relevant transport mechanism for durability of reinforced concrete structures exposed to aggressive environments such as XD2 or XD3 after EN 206 is capillary absorption of water with dissolved de-icing salts and its interaction with moisture and chloride diffusion. Limitation (decrease) of crack width is rather a concern with respect to capillary absorption. In the extreme case, the multiplication of cracks even if they are extremely narrow is increasing dramatically capillary absorption [17]. In this respect, the very high tensile strength of SH-UHPFRC, their limited shrinkage due to their very dense matrix and their significant viscous response to relax eigenstresses are a major advantage to totally avoid cracking (micro and macro) at serviceability.

This paper gives first an overview of more fundamental issues related to effects of cracking (micro or macro) on durability of cementitious materials with relevant conclusions for the selection of suitable materials for durable structures. In a second step, the mechanical performance under tension of SH-UHPFRC is described in terms of strength and deformability and examples of optimized formulations are given. Finally recent successful applications of SH-UHPFRC to the maintenance of existing RC structures are briefly presented and an outlook for future development needs is proposed.

\section{Effects of Cracking on Durability}

\subsection{General}

Cracking in reinforced concrete structures has consequences on durability at two levels. At the first level, one needs to determine the effect of the presence of cracks, distribution, type (through crack or bending cracks) and opening (microcracks, macrocracks) on transport phenomena (diffusion, permeation under pressure gradients or capillary absorption). At the second level, the influence of cracking on corrosion phenomena (or more generally on deterioration mechanisms) has to be examined.

Practice has shown that most detrimental cracks for reinforced concrete structures are through cracks (i.e. they fully cross a structural member) [18-19], often induced under direct tensile loading such as thermomechanical effects at early age on concrete 
at different ages. Keller [18] studied over 400 concrete cores taken on bridges throughout Switzerland. Over 6600 measurement values, no correlation was found between crack width and corrosion progress. A similar trend was found by other authors [20-22]. The presence of through cracks was the major cause of severe corrosion damage to rebars.

\subsection{Effects on Transport Mechanisms}

\subsubsection{Permeability to Liquids under Pressure Gradients}

All studies on the effect of crack width on permeability with respect to liquids of cementitious materials, whatever their type, converge on a similar result: after 0.05 to $0.1 \mathrm{~mm}$ crack width the permeability to water under pressure starts increasing at a much faster rate with increasing crack width [23-26]. The results of all those investigations are obviously very much linked to the crack features and patterns and to a lesser extend to the investigated materials.

\subsubsection{Capillary Absorption}

The effect of crack width on capillary absorption is reversed compared to permeability under pressure gradients: finer cracks lead to higher capillary absorption and are thus more detrimental. Lunk et al. [27] investigated the effect of various configurations of crack surfaces and different curing of concrete on the capillary absorption. These authors showed that finer cracks induce higher capillary absorption and also that a cover concrete with a limited curing (prevented from desiccation) of 2 days has much more capillary absorption than a concrete with a longer curing. This effect, linked to microcracking induced by premature exposure to desiccation, was also observed by Hearn [28]. Similarly, François et al. [29-30] observed that the stress level in rebars had a clear influence on the apparent chloride diffusion in reinforced concrete members, also due to the progressive damage induced in the surrounding concrete by increasing stress levels in the reinforcement bars. The trend was similar for normal, high performance or very high performance concrete.

Sahmaran et al. [17] studied the effect of the progressive development of microcracking in SHCC on the capillary absorption and sorptivity with and without a water repellent agent added to the fresh mix. Without water repellent agent, in the strain hardening range, the increasing number of finely distributed microcracks severely increased the cap- illary absorption of the tested materials. With a water repellent agent however, the increase of the number of microcracks had a small influence on capillary absorption of SHCC.

These capillary absorption effects are likely to be amplified under cyclic loading encountered in structures, with possible "pumping" of liquids during "crack opening and partially closing" cycles.

Capillary absorption of water (pure or with dissolved detrimental substances) combined with moisture and ion diffusion appears to be the relevant transport mechanisms with respect to the durability of reinforced concrete structures. Finer crack width and multiple microcracks are more detrimental for this transport process. Thus limitation of crack width and multiplication of microcracks are not a suitable way to prevent water penetration.

\subsection{Effects on Corrosion Processes}

The corrosion of reinforcement bars, induced by chlorides in de-icing salts, is one of the major causes of deterioration of reinforced concrete (RC) structures in many countries. Fig. 1 schematically represents (a) the critical factors necessary to trigger and fuel corrosion and (b) the evolution with time of the chloride-induced corrosion process in cracked and uncracked concrete, adapted from [30]. In uncracked concrete, curve (1), after Tuutti [31], the initiation phase is followed by the propagation phase. In cracked concrete with non-through cracks, within limits of crack openings up to $0.4 \mathrm{~mm}$, curve (2), the corrosion propagation has three phases. In phase (2a) the corrosion mechanism starts at the crack tip with a high rate of propagation. In phase ( $2 b)$, the corrosion rate is mostly controlled by the permeability of the cover concrete, nearby the crack, above the cathodes, to oxygen and moisture, and not by the crack opening. If the permeability of the cover concrete is low, the ingress of water and oxygen is slow and the corrosion rate is slowed down at the cathode. Further, the permeability of cover concrete in reinforced concrete is significantly influenced by the stress level of the reinforcement bars and the associated microcracking $[24,29,30]$. In phase $(2 \mathrm{c})$, once chlorides have reached the reinforcement bar in uncracked zones, nearby the crack, in a sufficient concentration, there is general corrosion propagation and the corrosion rate significantly increases. In through-cracked concretes, curve (3), no beneficial phenomena can decrease the corrosion rate once corrosion is initiated. 


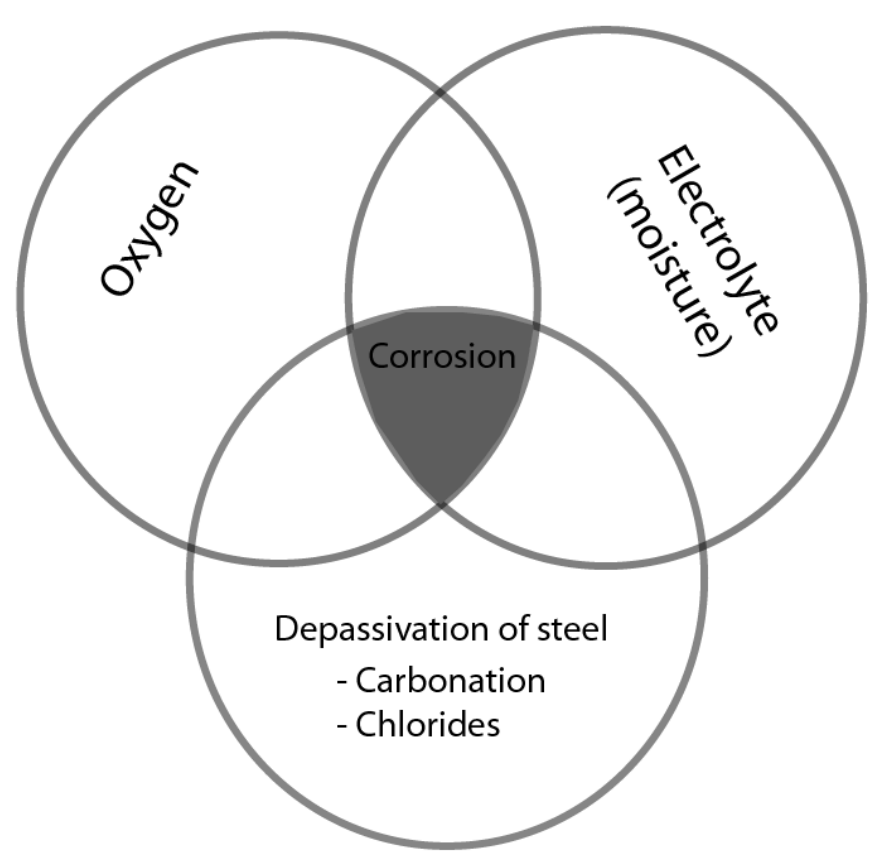

a)

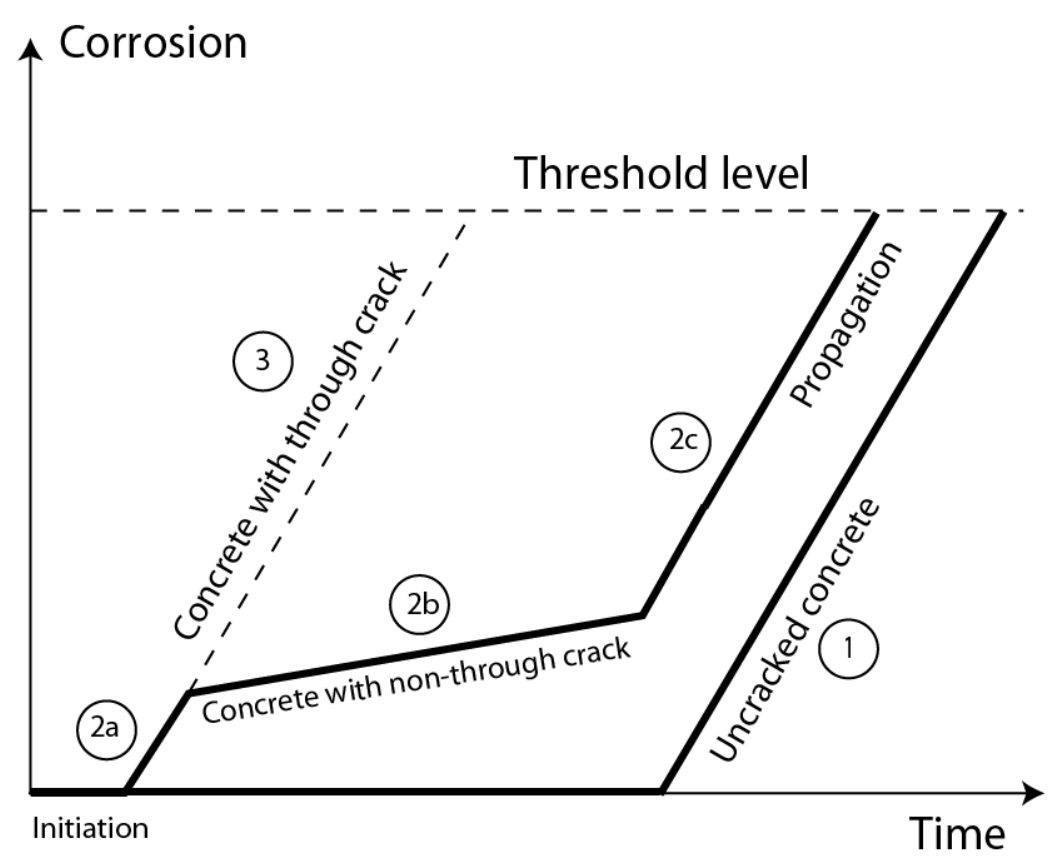

b)

Figure 1: (a) necessary factors for corrosion, (b) schematic evolution of the chloride induced-corrosion process as a function of time and cracking, adapted from [30]

The transport properties of the cover concrete appear to be the decisive parameter for the resistance to corrosion, not only in the case of non-cracked concretes, but also in the case of cracked concretes with non-through cracks and crack openings up to around $0.4 \mathrm{~mm}$.
All deterioration phenomena require the presence of moisture and/or oxygen. It is thus clear that the resistance to penetration (combination of depth and transport properties such as water and gas transport under pressure as well as capillary absorption of liquids) of the cover concrete is the most important parameter for the durability of reinforced concrete structures in corrosive environments. 


\section{Mechanical Performance of SH-UHPFRC}

\subsection{Introduction}

UHPFRC were originally developed with focus on the optimization of their ultra dense matrix, with a special attention to the increase of the compressive strength, above $200 \mathrm{MPa}[1,2,14,32]$. This led automatically to a dramatic decrease of the intrinsic permeability and capillary absorption, by optimization of the packing of grains with micro fillers such as quartz flour and silica fume and decrease of the water/binder ratio.

Many different types of UHPFRC recipes with various matrices and fibrous mixes are currently applied or under development worldwide. Very few or almost none, however, satisfy at the same time the conditions of tensile strain hardening, low permeability, high tensile and compressive strength and self compacting character needed for cast in situ applications.

The trend is currently clearly to use local materials and by-products of the industry such as fly ash, Ground Granulated Blast Furnace Slag - GGBFS and combinations of them to replace large quantities of cement. However, most often, the workability barrier linked to cement/superplasticiser compatibility issues remains an obstacle to the use of an efficient fibrous mix to achieve true tensile strain hardening and/or other drawbacks are encountered (higher shrinkage, limited availability of the materials, variability of the composition of the industrial by-products, high scatter of properties due to an insufficient fibrous mix).

Denarié et al. [33] proposed a general methodology for the formulation of SH-UHPFRC from local components, based on the massive use of limestone filler to replace clinker, which is not used for hydration. Thanks to the dramatic improvement of workability provided by limestone filler, SH-UHPFRC recipes based on local components become possible in most countries. Finally, the global warming impact by $\mathrm{CO}_{2}$ emission of these "ECO-UHPFRC" is significantly reduced, and over the whole life cycle, rehabilitations with ECO-UHPFRC have a much lower impact than traditional methods. [34].

This method of formulation has been applied successfully to the rehabilitation of a bridge in Slovenia in 2009 [34], and is now spreading in Switzerland.

\subsection{Optimization of Strength}

As shown by Rossi [3-5], a combination of different types of fibres (length, geometry, aspect ratio, dosages and materials) gives most freedom to optimize strength, deformability and workability of UHPFRC. Micro fibres (like steel wool - length of a few $\mathrm{mm}$ ) act at the material level and increase the apparent tensile strength. They have a dominant influence on the resistance of the material. Macro fibres (10 $\mathrm{mm}$ and over), act at the structural level, they increase the deformability of the composite. Note that microfibers also contribute indirectly to the deformability of the composite by improving the pull-out response of the macro fibres [6].

The synergetic effect of multiple fibre types is illustrated in Fig. 2 after [35]. The uniaxial tensile behaviour of two different recipes of the UHPFRC CEMTEC $_{\text {multiscale }}{ }^{\circledR}$ type [5], has been determined by means of a rigid fixed ends tensile test, on un-notched dumbbell specimens with a cross section of $50 \times 100 \mathrm{~mm}$ in their central part of $350 \mathrm{~mm}$ length. The scatter range and average curve are shown on Fig. 2a for mix CM23, with emphasis on the strain-hardening domain. One can note the high tensile strength of the material, over $10 \mathrm{MPa}$ and the low scatter of the results.

The average curves from five tests for each material are represented on Fig. $2 b$ showing a range of possible strain hardening responses for SH-UHPFRC. Both recipes are self-compacting.

- Recipe CM0 is reinforced with $468 \mathrm{~kg} / \mathrm{m}^{3}$ of a single type of $10 \mathrm{~mm}$ long steel fibres with an aspect ratio of 50 . It has a water/binder ratio of $0.140,1051 \mathrm{~kg} / \mathrm{m}^{3}$ cement, a fluid consistency (slump-flow $=700 \mathrm{~mm}$ ) and is self-levelling.

- Recipe CM23 has more binder $\left(1437 \mathrm{~kg} / \mathrm{m}^{3}\right.$ cement) and a lower water-binder ratio $(0.125)$. It is reinforced by a multilevel fibrous mix of macro steel fibres $(10 \mathrm{~mm}$ long, aspect ratio 50) and microfibres (steel wool) with a total dosage of $705 \mathrm{~kg} / \mathrm{m}^{3}$. It can hold a slope of the substrate up to $2.5 \%$.

The effect of the addition of microfibres is revealed by three aspects: (1), the significant increase of the pseudo-elastic domain from 8 to above $11 \mathrm{MPa}$, (2) the increase of the strain hardening domain, (3) the increase of the load carrying capacity in the descending branch due to the indirect action of the microfibres on the progressive pull-out of the macro fibres [6]. 


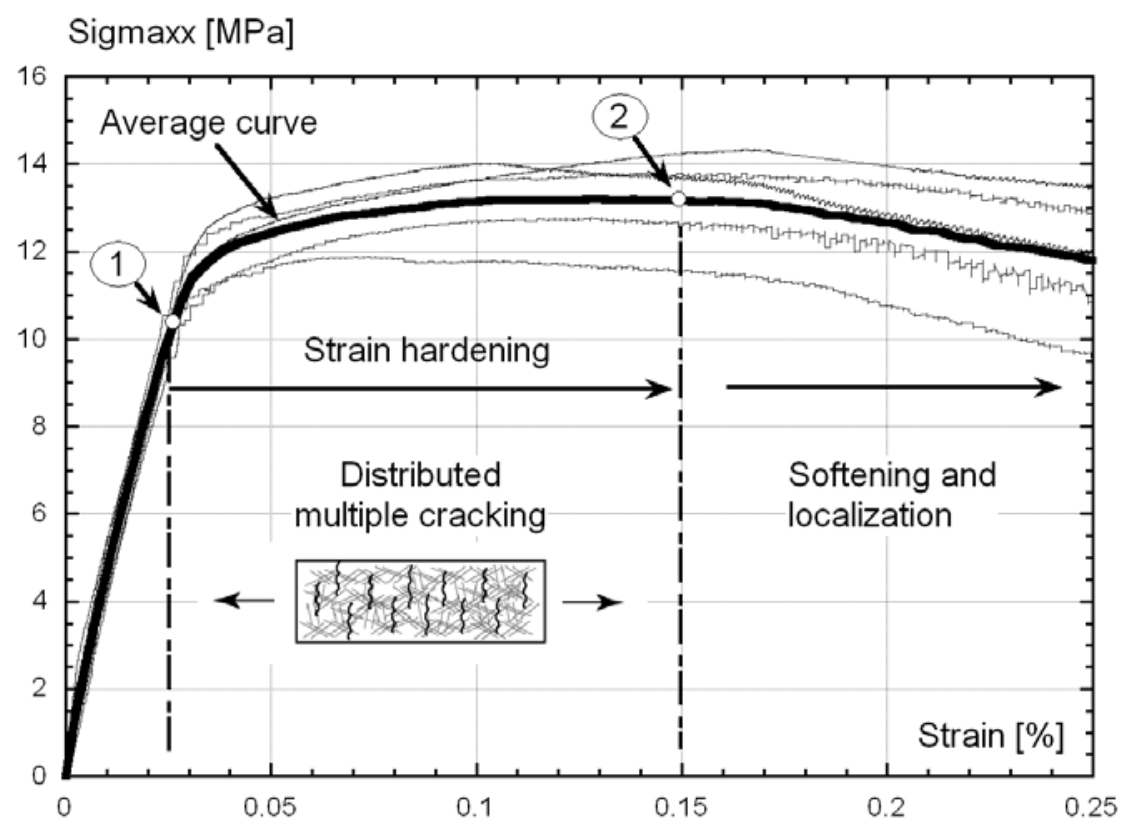

a)

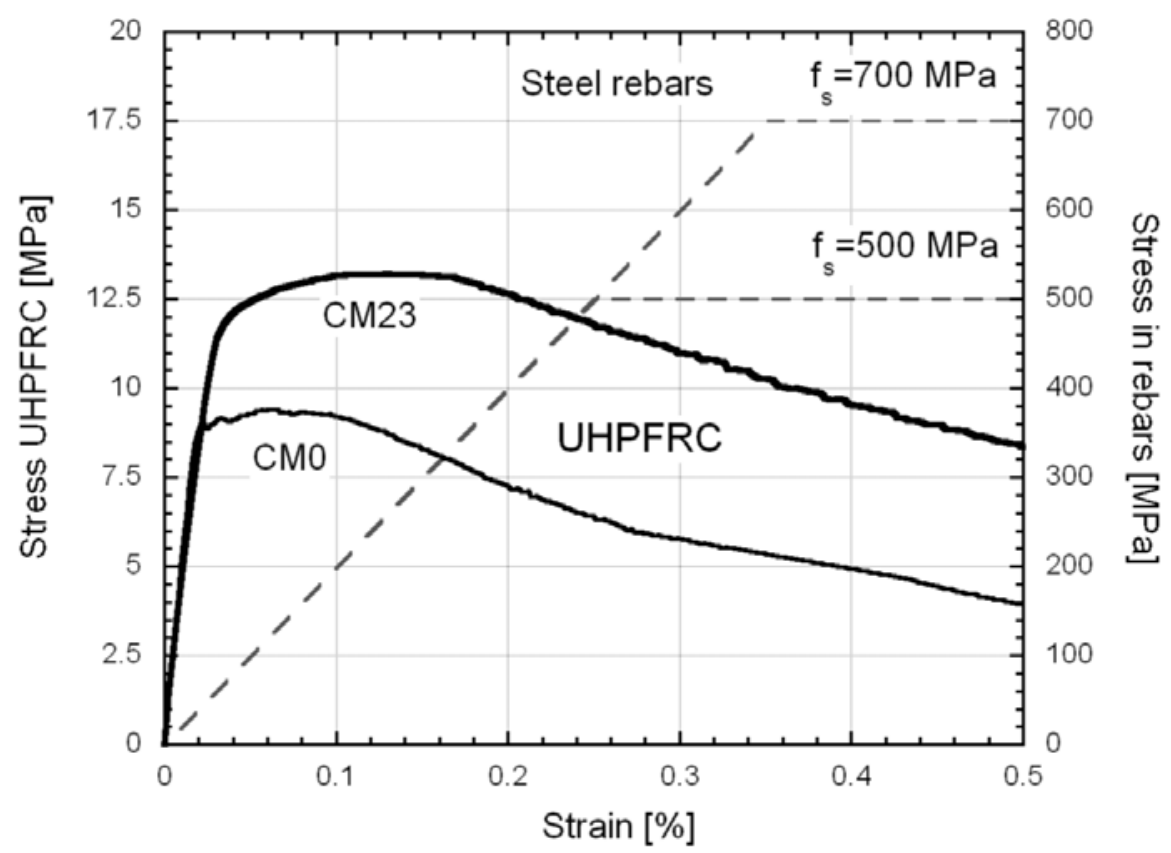

b)

Figure 2: $\quad$ Tensile behaviour of two UHPFRC recipes, $C E M T E C_{\text {multiscale }}{ }^{\circledR}$, unnotched tensile tests on dumbbell specimens, fixed rigid boundary conditions, average curves at 28 days [35], (a) scatter and average curve for mix CM23, (b) comparison of average curves for mixes CM0 and CM23

\subsection{Deformability}

The sensitivity of the tensile strain hardening response to the chosen fibrous mix is illustrated by the results of the meso-mechanical model from Wuest [36], that can simulate the tensile response of a UHPFRC as a function of its matrix (specific fracture energy and statistical variation of tensile strength), and fibrous mix (fibre type, dosage and coefficient of orientation). This model is able to predict very accurately the response observed in uniaxial tensile tests for different kinds of SH-UHPFRC and also SHCC with synthetic fibres. In a further step, the model was applied to investigate the effect of the fibre dosage on the extend of the tensile hardening response $\varepsilon_{\mathrm{u}, \max }$ for different fibre types. 


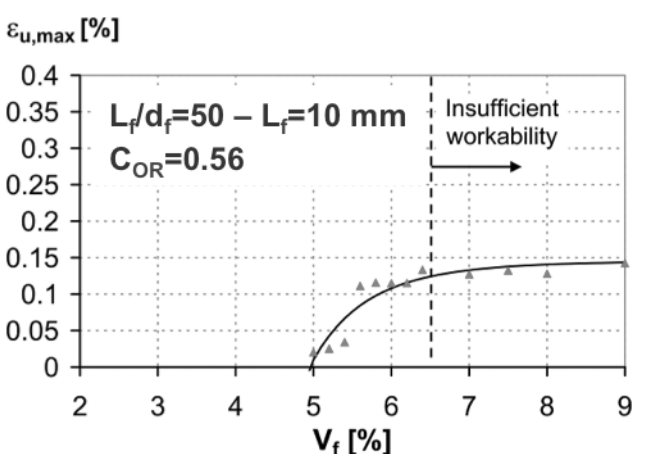

a)

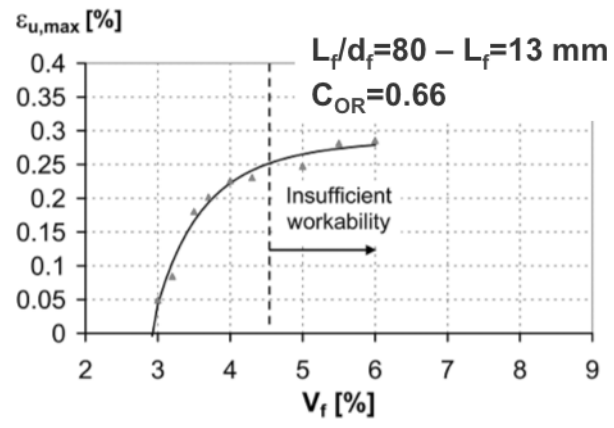

b)

Figure 3: Extend of the tensile strain hardening domain as a function of fibre dosage for two fibre types with different length and aspect ratio, calculated, after [36] $-\mathrm{C}_{\mathrm{OR}}=$ coefficient of orientation. Both cases correspond to the same casting in a dumbbell specimen form

The coefficients of orientation of the macro fibres were determined experimentally by stereological methods applied to cuts in the specimens cross sections [37]. Both cases correspond to the same dumbbell geometry and casting conditions. The results are illustrated on Fig. 3 for two types of fibres that lead a priori, according to [16], to a tensile strain hardening response for respectively between 5 and $7 \%$ and 3 and $5 \%$ vol fibres.

The mix with less fibres with a higher aspect ratio (13 mm length, diameter $0.16 \mathrm{~mm}$ ), case (b), although it delivers a larger strain hardening for a high dosage, is much more sensitive to a variation of the fibre dosage, in its applicability range of workability (mixes up to $3.5 \%$ Vol.). For a dosage of $3.5 \%$, a change of $0.5 \%$ vol., fibres in the mix can decrease the extent of hardening by a factor of two and eventually make it vanish completely. At the contrary, for fibres $10 \mathrm{~mm}$ long, aspect ratio 50, with a dosage of $6 \%$ (totally compatible with a wide range of workability) a decrease of $0.5 \%$ of the fibre dosage does not significantly decrease the hardening domain, however, before $5.2 \%$ vol. fibres, no tensile hardening is expected.

This illustrates the fact that the most robust fibre mix to achieve SH-UHPFRC is not the one with the lowest fibre dosage and very high aspect ratio of fibres. At the contrary, the absolute amount of fibres is also a critical parameter to guarantee a low scatter and thus high design values (fractile) of mechanical performances [3].

Finally, the deformability of the SH-UHPFRC presented in Fig. $2 \mathrm{~b}$ can be compared to the yield strain of steel rebars for B500 and B700 steels. In the strain hardening domain of SH-UHPFRC, their tensile load carrying capacity can be superimposed to that of steel rebars to obtain a high performance Reinforced UHPFRC i.e. R-UHPFRC [38-39].

UHPFRC can be used advantageously at SLS up to their pseudo-elastic limit of 8 to $12 \mathrm{MPa}$ without any detrimental effect on their protective function. Considering their elastic modulus in the range of 45 to $50 \mathrm{GPa}$, one gets a potential elastic deformability in the range of $0.2 \%$, more than double of that of ordinary concrete (the same actually applies to a SHCC with a tensile strength of $4 \mathrm{MPa}$ and elastic modulus around $20 \mathrm{GPa}$ ).

This value should be compared with the maximum free shrinkage of SH-UHPFRC in the range of 0.6 to $0.8 \%$ and their stress relaxation capacity of a factor of 2 at least (creep coefficient of 0.8 to 1 at 28 days, without thermal treatment), Fig. 4. Considering the degree of restraint (ratio of the eigenstresses developed in the structural member with respect to the eigenstresses in the case of total restraint of all axial and flexural degrees of freedom) of most structural applications of cast on site SH-UHPFRC, in the range of 50 to $80 \%$, the strength of SH-UHPFRC only and their relaxation capacity almost guarantees that they prevent cracking under the eigenstresses imposed by their maximum shrinkage. This demonstrates that, at least for SH-UHPFRC, at SLS, the relevant aspect of the mechanical response with respect to durability is firstly a high tensile strength, and secondly a significant deformability as an extra benefit. In contrast to ordinary concrete, SH-UHPFRC has a favourable deformational balance between restrained deformations under shrinkage and viscous and strain hardening deformation capacity that helps to obtain crack free structures [40-43].

From the point of view of fatigue loading and also at Ultimate Limit State (ULS), the extra deformability offered by the tensile response of SH-UHPFRC, in the range of several \%o is also very welcome and useful, especially in combination with rebars. The range of their strain hardening response is actually exactly in the useful domain for most structural applications. 


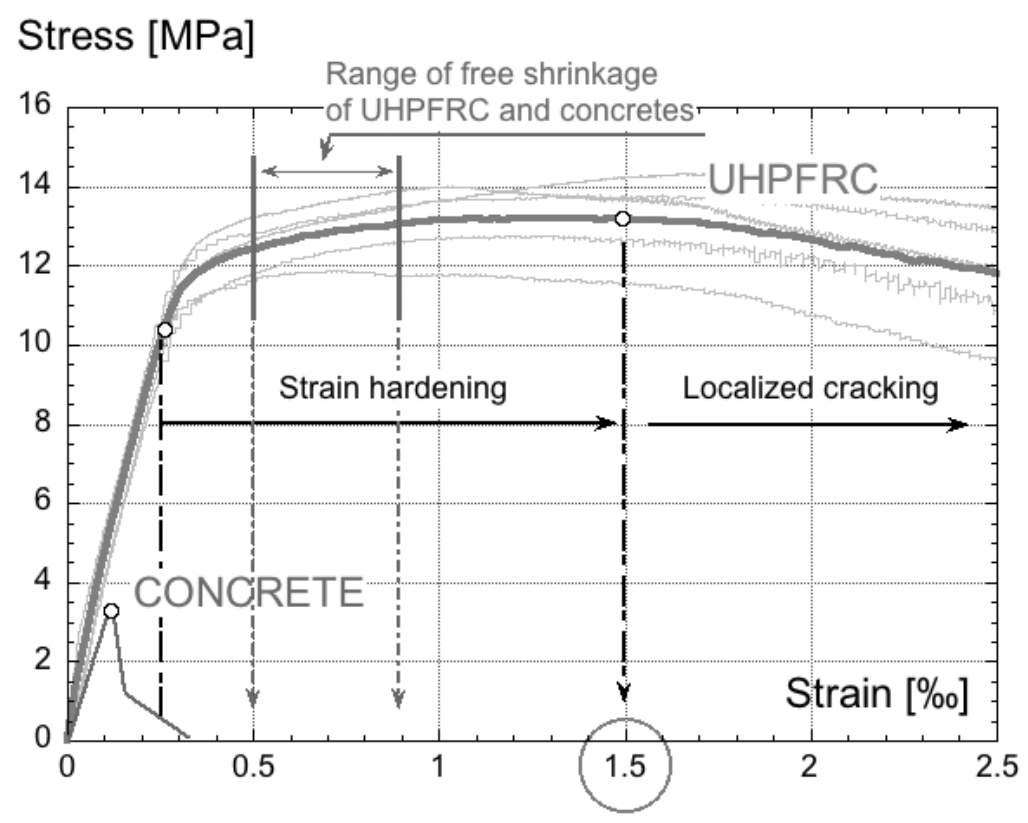

Figure 4: Extend of the tensile strain-hardening domain of SH-UHPFRC (CEMTEC CM23) and comparison with deformability of concrete and range of free shrinkage of UHPFRC and concrete

\section{$4 \quad$ Structural Applications}

\subsection{Concept of Application and Valida- tions}

The concept of application of SH-UHPFRC for the rehabilitation of structural members, proposed by Brühwiler in 1999 [44], is schematically illustrated on Fig. 5a. An "everlasting winter coat" is applied on the bridge superstructure in zones of severe environmental and mechanical loads (exposure classes XD2, XD3) and only where the UHPFRC is worth using. Critical steps of the construction process such as application of waterproofing membranes or compaction by vibration can be prevented, and the associated sources of errors avoided. The construction process becomes simpler, quicker, and more robust, with an optimal use of composite construction.

The waterproofing capabilities of SH-UHPFRC exempt from applying a waterproofing membrane. Thus, the asphalt pavement can be applied after only 8 days of moist curing of the UHPFRC. This constitutes a very significant time saving with respect to the drying period of up to 3 weeks necessary prior to the application of a waterproofing membrane for a usual mortar or concrete.

Further, the thickness of the asphalt layer can be limited to the absolute minimum required for the traffic loads. It is not needed to increase it to apply weight on the waterproofing membrane to prevent the formation of air pockets.

When it is required, the combination of the protective properties and deformation capability of SH-UHPFRC (Fig. 5b) with the mechanical performance of reinforcement bars (normal or high grade) provides a simple and efficient way of increasing the stiffness and load-carrying capacity with compact cross sections.

This original conceptual idea has been validated by means of extensive research aimed at characterizing UHPFRC materials and the structural behavior of composite structural members [38, 39].

This concept is very well suited for bridges and reinforcement of slabs in buildings and can also be implemented for galleries, tunnels or retaining walls.

\subsection{Applications}

By December 2011, 14 applications of SH-UHPFRC to protect or reinforce bridges or slabs in industrial buildings, alone or combined with rebars, have been performed successfully since 2004 in Switzerland and one in Slovenia in 2009 as mentioned above [34, 44].

Fig. 6 shows one of the most recent applications of SH-UHPFRC in Switzerland close to Geneva; in late fall 2010 with slopes of $5 \%$ of the bridge deck. 


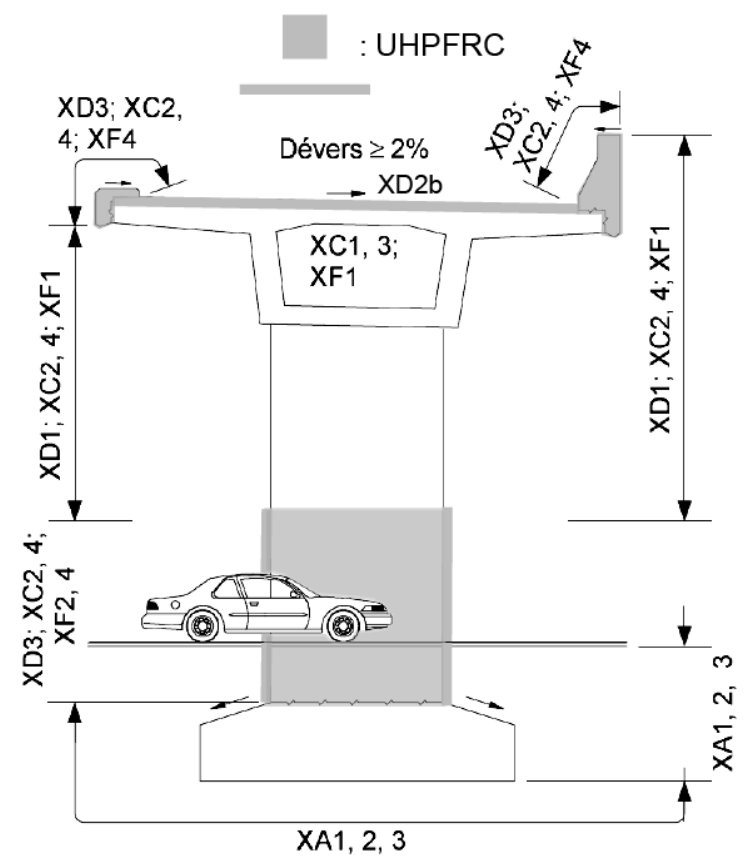

a)
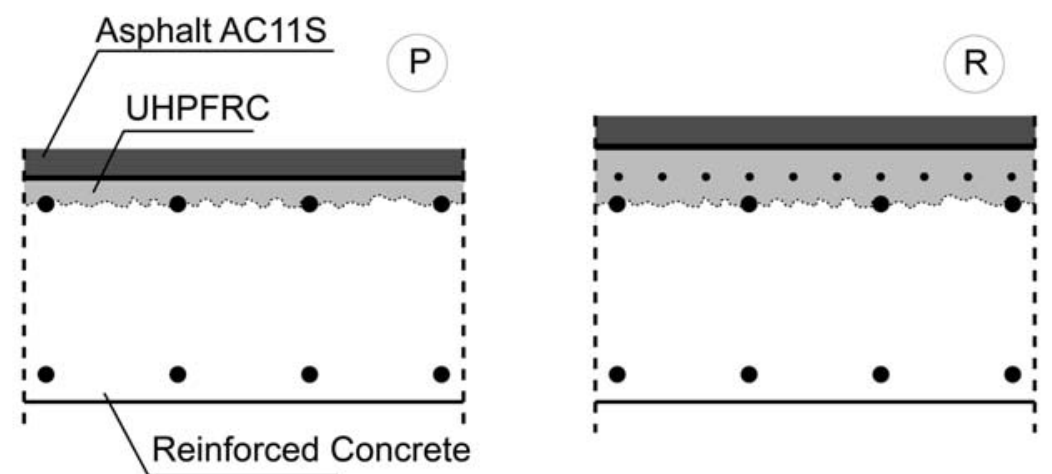

b)

Figure 5: (a), Concept of application of the local "hardening" of bridge superstructures with SH-UHPFRC [44], (b), Applications of SH-UHPFRC for protection "P", or reinforcement, combined with rebars, "R"

The mix, based on local components, has $650 \mathrm{~kg} / \mathrm{m}^{3}$ cement and an equal quantity of limestone filler. The optimized fibrous mix has $353 \mathrm{~kg} / \mathrm{m}^{3}$ of $10 \mathrm{~mm}$ long, $0.16 \mathrm{~mm}$ diameter straight steel fibres. The mix is self-compacting and can be cast on slopes from 5 to $10 \%$ inclination, in all seasons. This application of SH-UHPFRC helped the owner to save $30 \%$ on construction costs by avoiding a costly and long re-profiling procedure of the concrete road in front and behind the bridge, to accommodate the challenging position of the rebars, unexpectedly close to the road surface in the upper face of the deck.

Another application was realized in 2011 with similar SH-UHPFRC mixes in Switzerland on the steep road to a pass with slopes over $10 \%$ and very limited disturbances for road users thanks to the fast construction works.

\section{Conclusions and Outlook}

- Within a range of up to $0.4 \mathrm{~mm}$, crack width is not the relevant parameter to control durability of structures. It is rather the presence of through cracks or the resistance to penetration of liquids and gases of the concrete cover adjacent to non-through cracks.

- For non through cracks, the resistance to penetration of liquids and gases of the cover concrete in uncracked zones or nearby macro cracks is the most important parameter for the propagation of corrosion phenomena with time.

- It is thus better to avoid cracks by using suitable materials such as SH-UHPFRC, or control their width so that it remains smaller than 


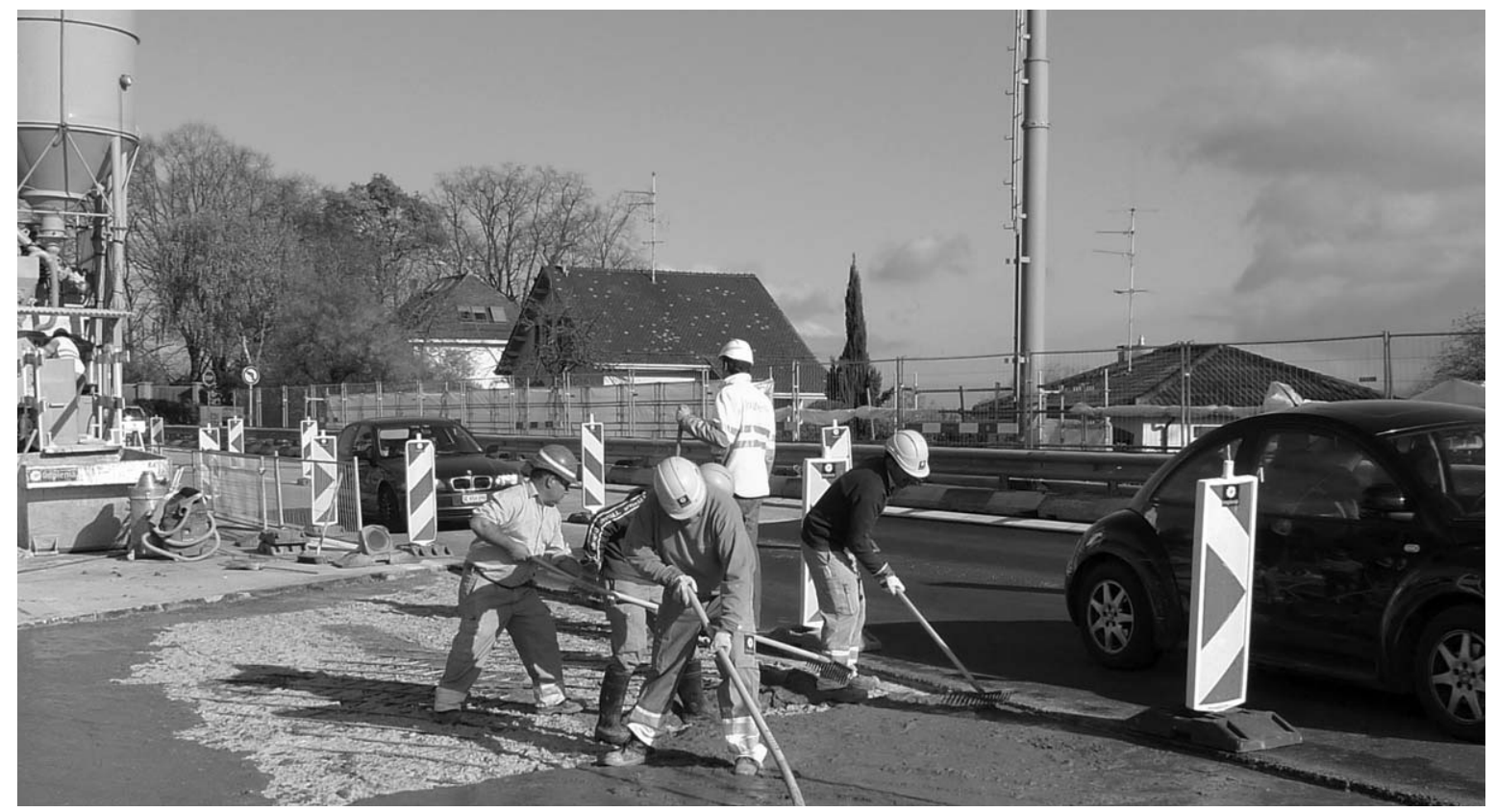

Figure 6: Underpass "Creux de Genthod" - nearby Geneva $(\mathrm{CH}), 2010$, rehabilitation of a bridge deck with SH-UHPFRC, slope $5 \%$, average external temperature $5^{\circ} \mathrm{C}$

$0.4 \mathrm{~mm}$ and guarantee the lowest possible permeability to gases and water sorptivity of cover concrete by any means (suitable combination of density of cover concrete and thickness of cover).

- SH-UHPFRC with their very dense matrix, high tensile strength, limited shrinkage and significant relaxation potential are most suitable to avoid cracks in structures, thanks to their high tensile strength and deformability.

- SH-UHPFRC, with their extremely low permeability to water and gases and very low sorptivity, applied in thin layers of 25 to 50 $\mathrm{mm}$ offer compact cross sections with limited dead weight for an impervious covercrete with necessary covers over rebars of only $20 \mathrm{~mm}$ in most aggressive conditions.

- SH-UHPFRC can be developed with a wide range of matrices using local components, a large quantity of Supplementary Cementitious Materials (SCM) as clinker replacement, and a fibrous mix to offer a tensile strain hardening capacity of several per mille and a tensile strength from 10 to $20 \mathrm{MPa}$.

- SH-UHPFRC have been applied successfully since 2004 cast on site or prefabricated in fifteen construction sites in Switzerland or Slovenia, to rehabilitate bridges or buildings, in most challenging conditions of climate and slopes of substrates.

- Combination of SH-UHPFRC with rebars offers an efficient way to produce highly durable R-UHPFRC tensile membranes to reinforce existing structures.

- The next step and challenge is to link all progress from the last 30 years on strength, deformability, durability and rheology of cementitious composites with the latest developments in chemistry of binder to develop very fast hardening materials for "stealth" construction sites, and making extensive use of SCM to remain sustainable.

\section{Acknowledgements}

We gratefully acknowledge contributions of the following current and former members of the UHPFRC team of MCS-EPFL: Prof. J.P. Charron, Dr. K. Habel, Dr. A. Herwig, Dr. A. Kamen, Mr. H. Kamyab, Mrs T. Noshiravani, Dr. C. Oesterlee, Dr. H. Sadouki, Dr. A. Switek, Dr. J. Wuest, and also of our partners in EU project Arches WP 5: Dr A. Šajna, Mrs J. Šuput, Mrs L. Resčič, Dr. P. Rossi, Mrs L. Cernilogar. 
Financial support of Swiss National Science Foundation, Swiss Secretary of Education and Research $\left(\mathrm{EU} 5^{\text {th }} \mathrm{FP}\right)$, Committee of Technology and Innovation, Cemsuisse, Holcim, Swiss Steel AG, the Swiss Federal Roads Office, the European Union (EU $6^{\text {th }}$ FP) is gratefully acknowledged.

The willingness of cooperation of the road administrations of Swiss cantons Aargau, Geneva, Graubünden, Luzern, Vaud, Wallis, Zürich, and of the municipality of Bovec (Slovenia), as well as of the representatives of the town of Geneva, made the SH-UHPFRC applications described or mentioned in this contributions possible.

\section{References}

1. H. H. Bache, Fracture Mechanics in Integrated Design of New, Ultra-Strong materials and Structures, in Fracture Mechanics of Concrete Structures - From Theory to Applications, Report of RILEM Committee TC 90/FMA - Fracture Mechanics Applications, L. Elfgren Ed., Chapman \& Hall, London, 382-398 (1989)

2. P. Richard and M. Cheyrezy, Composition of Reactive Powder Concretes, Cement and Concrete Research 25, 1501-1511 (1995)

3. P. Rossi, High-Performance Multimodal Fiber Reinforced Cement Composites (HPMFRCC): The LCPC Experience, ACI Materials Journal 94, 478-483 (1997)

4. P. Rossi, Ultra-high performance fibre reinforced concretes (UHPFRC): an overview, P. Rossi and G. Chanvillard Editors, Proceedings of the Fifth International RILEM Symposium on Fibre-Reinforced Concretes, BEFIB'2000, Lyon, France, 87-100 (2000)

5. P. Rossi, A. Arca, E. Parant, P. Fakhri, Bending and compressive behaviours of a new cement composite, Cement and Concrete Research 35, 27 - 33 (2005)

6. E. Parant, Mécanismes d'endommagement et comportements mécaniques d'un composite cimentaire fibré multi-échelles sous sollicitations sévères: fatigue, choc, corrosion, Ph.D. thesis, Ecole nationale des Ponts et Chaussées, Paris (2003)

7. D. R. Lankard, Slurry Infiltrated Fiber Concrete (SIFCON): Properties and Applications, in Very High Strength Cement-Based Materials, Proceedings Materials Research Society Symposium, edited by J.F. Young, 42, MRS Pittsburgh, 277-286 (1985)
8. J. Zeng, P. Klingenberg and Z. Bayasi, Slurry Infiltrated Mat Concrete (SIMCON) for Rehabilitation of Bridges and Pavements, N. Krstulovic-Opara and Z. Bayasi Editors, ACI publication SP 185, High Performance Fiber-Reinforced Concrete in Infrastructural Repair and Retrofit, ACI, USA, 55-68 (2000)

9. S. Hauser and J. D. Wörner, DUCON, a Durable Overlay, H.W. Reinhardt and A.E. Naaman Editors, RILEM Proceedings of The Third International Workshop on High Performance Fibre Reinforced Cement Composites (HPFRCC 3), Mainz, Germany, 603-615 (1999)

10. V.C. Li, From micromechanics to structural engineering - The design of cementitious composites for civil engineering applications, Structural engineering/earthquake engineering 10, 37-48 (1993)

11. M. Maalej and V. Li, Introduction of Strain Hardening Engineered Cementitious Composites in design of Reinforced Concrete Flexural members for Improved Durability, ACI Structural Journal 92, 167-176 (1995)

12. V.C. Li, H. Horii, P. Kabele and Y.M. Lim, Repair and retrofit with Engineered Cementitious Composites, Engineering Fracture Mechanics 65, 317-334 (2000)

13. G. De Schutter, P. J. M. Bartos, P. Domone, J. Gibbs, Self-Compacting Concrete, CRC Press, Wiley, Taylor \& Francis group (2008)

14. F. de Larrard and T. Sedran, Optimization of Ultra-High-Performance Concrete by the Use of a Packing Model, Cement and Concrete Research 24, 997-1009 (1994)

15. F. de Larrard, Concrete Mixture Proportioning - A Scientific Approach, Modern Concrete Technology Series, 9, E \& FN SPON (1999)

16. A. Naaman, Strain hardening and deflection hardening fibre reinforced cement composites, A.E. Naaman and H.W. Reinhardt Editors, Proceedings HPFRCC 4, RILEM publications, Pro 30, 95-113 (2003)

17. M. Sahmaran and V. Li, Influence of microcracking on water absorption and sorptivity of ECC, Materials and Structures 42, 593-603 (2009)

18. T. Keller, Dauerhaftigkeit von Stahlbetontragwerken - Transportmechanismen und Auswirkung von Rissen, Bericht ETH-IBK Zürich $\mathbf{N}^{\circ}$ 184, Birkhäuser Verlag, Basel (1991) 
19. G. Hartl and W. Lukas, Untersuchungen zur Chlorideindringung in Beton und zum Einfluss von Rissen auf die Chloridinduzierte Korrosion der Bewehrung, Betonwerk + Fertigteiltechnik 7, 497-506 (1987)

20. K. Tuutti, Cracks and Corrosion, CBI forskning Fo, research report $\mathrm{n}^{\circ}$ 6:78, Stockholm, Sweden (1978)

21. G. Rehm, U. Nürnberger., B. Neubert, Chloridkorrosion von Stahl in gerissenem Beton, Deutscher Ausschuss für Stahlbeton 390 (1988)

22. P. Schiessl and M. Raupach, Laboratory studies and calculations on the influence of crack width on Chloride induced corrosion of steel in concrete, ACI Material Journal 94, 56-62 (1997)

23. M. Hoseini, V. Bindiganavile, N. Banthia, The effect of mechanical stresses on permeability of concrete: A review, Cement and Concrete Composites 31, 213-220 (2009)

24. C. Desmettre and J. P. Charron, Novel water permeability device for reinforced concrete under load, Materials and Structures 44, 1713-1723 (2011)

25. M. Lepech and V. C. Li, Water Permeability of cracked cementitious composites, Proceedings ICF11, $11^{\text {th }}$ International Conference on Fracture, Paper 4539 in Compendium of Papers CD-ROM, Turin, Italy, March 20-25 (2002)

26. J.-P. Charron, E. Denarié, E. Brühwiler, Transport properties of Water and Glycol in an Ultra High Performance Fiber Reinforced Concrete (UHPFRC) under high tensile deformation, Cement and Concrete Research 38, 689-698 (2008)

27. P. Lunk, T. Müller, F. H. Wittmann, Feuchtigskeits-und Ionentransport in gerissenen Stahlbetonbauteilen, Forschungsauftrag 85/90 auf Antrag der Arbeitsgruppe Brükkenforschung, Bericht OFROU $\mathrm{N}^{\circ} \mathbf{5 3 8}$, VSS, Schweiz (1998)

28. N. Hearn, Effect of shrinkage and load-induced cracking on water permeability of concrete, ACI Materials Journal 96, 234-241 (1999)

29. R. François and G. Arliguie, Reinforced Concrete: Correlation between Cracking and Corrosion, in Proceedings of the Second International CANMET Conference on the Durability of Concrete, Montréal, Canada, V.M. Mahlotra ed., 1221-1238 (1991)
30. R. François and G. Arliguie, Effect of microcracking and cracking on the development of corrosion in reinforced concrete members, Magazine of Concrete Research 51, 143-150 (1999)

31. K. Tuutti, Corrosion of Steel in Concrete, CBI forskning research, report fo $\mathbf{4 . 8 2}$, Stockholm, Sweden (1980)

32. N. Roux, C. Andrade, M. A. Sanjuan, Etude Expérimentale sur la durabilité des Bétons de Poudres Réactives, Annales de l'Institut Technique du Bâtiment et des Travaux Publics (ITBTP), Les Bétons de Poudres Réactives (BPR) à Ultra Haute Résistance (200 à $800 \mathrm{MPa})$, 532, Série Béton 320, 133-141 (1995)

33. E. Denarié, Recommendations for the tailoring of UHPFRC recipes for rehabilitation, Deliverable ARCHES D06, http://arches.fehrl.org (2009)

34. E. Denarié, G. Habert, A. Šajna, Recommendations for the use of UHPFRC in composite structural members - rehabilitation Log Čezsoški bridge. Deliverable ARCHES D14, http://arches.fehrl.org (2009)

35. E. Denarié and E. Brühwiler, Structural rehabilitations with Ultra High Performance Fibre Reinforced Concretes, International Journal for Restoration of Buildings and Monuments, Aedificatio 12, 453-465 (2006)

36. J. Wuest, E. Denarié, E. Brühwiler, Model for predicting the UHPFRC tensile hardening response, UHPC-2008: The Second International Symposium on Ultra High Performance Concrete, E. Fehling, M. Schmidt, S. Stürwald ed., Structural Materials and Engineering Series, 10, Kassel University Press, Germany, 153-160 (2008)

37. J. Wuest, E. Denarié, E. Brühwiler, L. Tamarit, M. Kocher, E. Galluci, Tomography Analysis of Fibre Distribution and Orientation in Ultra-High Performance Fibre Reinforced Concrete with High Fibre Dosages, Experimental techniques 33, 50-55 (2009)

38. K. Habel, E. Denarié, E. Brühwiler, Structural response of elements combining Ultra-High Performance Fiber Reinforced Concretes (UHPFRC) and reinforced concrete, ASCE Structural journal, November, 1793-1800 (2006)

39. C. Oesterlee, E. Brühwiler, E. Denarié, Tragverhalten von Verbundbauteilen aus bewehrtem UHFB und Stahlbeton, Betonund Stahlbetonbau 104, 462-470 (2009) 
40. K. Habel, E. Denarié, E. Brühwiler, Time Dependent Behaviour of Elements Combining UHPFRC and Concrete, Materials and Structures 39, 557-569 (2006)

41. A. Kamen, E. Denarié, E. Brühwiler, UHP$F R C$ tensile creep at early age, Materials and Structures 42, 113-122 (2009)

42. A. Kamen, E. Denarié, H. Sadouki, E. Brühwiler, Thermo-mechanical response of UHPFRC at early age - experimental study and numerical simulation, Cement and Concrete Research 38, 822-831 (2008)
43. A. Switek, Time-Dependent Response of Ultra High Performance Fibre Reinforced Concrete (UHPFRC) under Low to High Tensile Stresses, thèse EPFL $\mathrm{n}^{\circ} \mathbf{4 8 9 9}$, Lausanne, Suisse (2010)

44. E. Brühwiler and E. Denarié, Rehabilitation of concrete structures using Ultra-High Performance Fibre Reinforced Concrete, UHPC-2008: The Second International Symposium on Ultra High Performance Concrete, Kassel, Germany, March 05 - 07, 895-902 (2008)
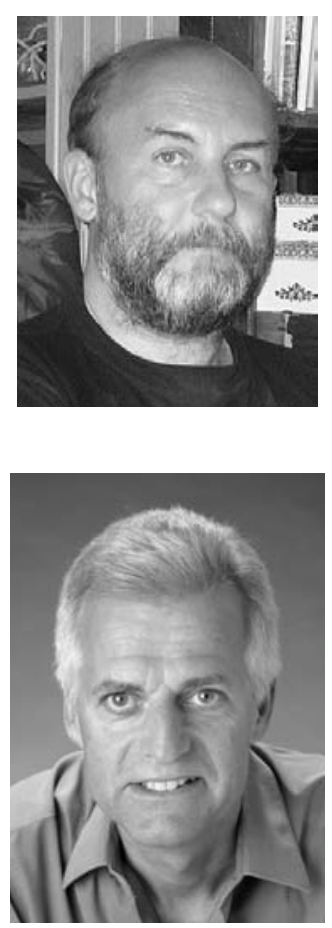

Dr. Emmanuel Denarié is a civil engineer, with a $\mathrm{PhD}$ in Materials Science. He worked for 3 years in a civil engineering company where he was in charge of the design of structures and the maintenance of bridges. He has 20 years experience on research and applications in the field of building materials, advanced concretes, and rehabilitation of reinforced concrete structures. He is since 2000 research associate in the Laboratory for Maintenance and Safety of structures, at Ecole Polytechnique Fédérale de Lausanne (EPFL), in charge of research activities on the application of concretes and advanced cementitious materials to the improvement of existing and new structures.

Address : Ecole Polytechnique Fédérale de Lausanne (EPFL), ENAC - MCS, GC B2 435, Station 18, CH-1015 Lausanne, Switzerland. E-mail: emmanuel.denarie@epfl.ch

Professor Dr. Eugen Brühwiler is a Professor at the Ecole Polytechnique Fédérale de Lausanne (EPFL) and director of MCS (Division of Maintenance and Safety of Structures) since 1995 . He received his civil engineering diploma and $\mathrm{PhD}$ from respectively ETH Zürich (1983) and EPFL (1988). After a two years post-doctoral stay at the University of Colorado in Boulder USA, he was with the Swiss Federal Railways in Zurich for four years working in the domain of maintenance and safety of railway bridges.

His research interests include the behaviour of cementitious materials and their application for the improvement of concrete structures, durability and safety issues of existing structures, in particular bridges.

Address : Ecole Polytechnique Fédérale de Lausanne (EPFL), ENAC-MCS, Station 18, CH-1015 Lausanne, Switzerland. E-mail: eugen.bruehwiler@epfl.ch 
